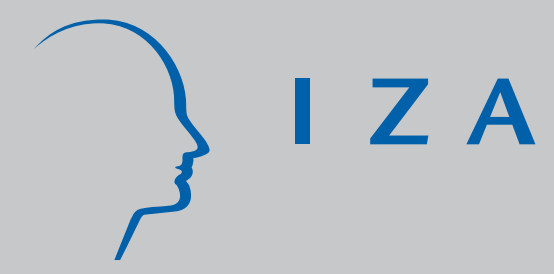

IZA DP No. 3873

Implicit Prejudice and Ethnic Minorities:

Arab-Muslims in Sweden

J ens Agerström

Dan-Olof Rooth

December 2008 


\title{
Implicit Prejudice and Ethnic Minorities: Arab-Muslims in Sweden
}

\author{
Jens Agerström \\ Kalmar University \\ Dan-Olof Rooth \\ Kalmar University \\ and IZA
}

Discussion Paper No. 3873
December 2008

IZA

P.O. Box 7240

53072 Bonn

Germany

Phone: +49-228-3894-0

Fax: +49-228-3894-180

E-mail: iza@iza.org

Any opinions expressed here are those of the author(s) and not those of IZA. Research published in this series may include views on policy, but the institute itself takes no institutional policy positions.

The Institute for the Study of Labor (IZA) in Bonn is a local and virtual international research center and a place of communication between science, politics and business. IZA is an independent nonprofit organization supported by Deutsche Post World Net. The center is associated with the University of Bonn and offers a stimulating research environment through its international network, workshops and conferences, data service, project support, research visits and doctoral program. IZA engages in (i) original and internationally competitive research in all fields of labor economics, (ii) development of policy concepts, and (iii) dissemination of research results and concepts to the interested public.

IZA Discussion Papers often represent preliminary work and are circulated to encourage discussion. Citation of such a paper should account for its provisional character. A revised version may be available directly from the author. 
IZA Discussion Paper No. 3873

December 2008

\section{ABSTRACT \\ Implicit Prejudice and Ethnic Minorities: Arab-Muslims in Sweden ${ }^{*}$}

This paper examines whether Swedish employers implicitly/automatically hold i) negative attitudes toward Arab-Muslims, an ethnic minority group subjected to substantial labor market discrimination in Sweden, and more specifically ii) associate members of this minority group with lower work productivity, as compared to native Swedes. Adapted versions of the Implicit Association Test (IAT; Greenwald et al., 1998) designed to measure implicit attitudes and productivity stereotypes toward Arab-Muslims were used. Corresponding explicit measures were administered. The results clearly show that employers have stronger negative implicit attitudes toward Arab-Muslims relative to native Swedes as well as implicitly perceive ArabMuslims to be less productive than native Swedes. Notably, the explicit measures reveal much weaker negative associations. Whereas traditional research has focused on selfconscious, explicit work related attitudes toward various ethnic minority groups, this study offers a novel approach to understanding work related prejudice.

JEL Classification: J70

Keywords: implicit, attitudes, stereotypes, discrimination, ethnicity

Corresponding author:

Dan-Olof Rooth

Department of Economics

Kalmar University College

39182 Kalmar

Sweden

E-mail: Dan-Olof.Rooth@hik.se

\footnotetext{
* We thank seminar participants at IFAU for valuable comments. A research grant from IFAU is gratefully acknowledged. Rickard Carlsson, Klara Johansson, Terese Johansson and Markus Mowitz provided excellent research assistance.
} 


\section{Introduction}

A great deal of international research (e.g., Bertrand \& Mullainathan, 2004) has documented widespread labor market discrimination against various ethnic minorities despite the fact that individuals, companies, and organizations recognize the economic implications of judging job candidates on the basis of group membership rather than merit. Recent research has also found ethnic discrimination to exist in the Swedish labor market. By sending fictitious applications to real job openings, Carlsson and Rooth (2007) present evidence of ethnic discrimination in the recruitment process by employers. Applications with identical skills were randomly assigned Arab-Muslim- or Swedish-sounding names. It was found that applications with a Swedishsounding name received fifty percent more callbacks for a job interview.

Although the existence of ethnic discrimination is rather well corroborated, its causes have received much less empirical attention. Economists, much like psychologists, have generally assumed that this discrimination can be traced back to people's explicit and consciously mediated perceptions of the discriminated target group (see e.g., Altonji \& Blank, 1999; Devine, 1989). However, recent research in the field of social cognition has found that unconscious/automatic processes can exert strong influences on behavior in many different contexts (see e.g., Bargh et al., 1996; Uhlman \& Cohen, 2007; Phelps, 2006).

A widely used test that measures individual differences in automatic associations between concepts and attributes is the Implicit Association Test (IAT; Greenwald, McGhee, \& Schwartz 1998). Interestingly, besides showing the existence of automatic attitude and stereotype bias toward various social groups, the IAT has been found to predict behavioral outcomes in a number of different domains (Greenwald et al., in press). For example, it has been shown that negative automatic associations toward Black people have been found to predict the degree to which people make negative judgments of ambiguous behaviors performed by a Black target (Rudman and Lee, 2002). Furthermore, more negative automatic associations toward Blacks successfully predicted more negative nonverbal behaviors, such as less speaking time and less smiling, during an interaction with a Black researcher relative to a White researcher (McConnell and Leibold, 2001). Green et al. (2007) demonstrated that implicit anti-Black attitudes and stereotypes predicted physicians' medical decisions in that they were more reluctant to prescribe medications to African-American patients diagnosed with the same condition as White American patients. 
Importantly, it has been documented that in certain domains (e.g., prejudice) implicit attitudes may be better predictors of behavior than explicit ones (Greenwald et al., in press). This raises the question whether implicit, non reflective associations regarding work productivity could be important antecedents of discriminatory behavior observed in the labor market. Before attempting to assess the potential impact of implicit cognitions on discriminatory behavior, however, it is necessary to establish whether those ethnic groups being subjected to discrimination are indeed implicitly associated with more negative attributes in the first place. Thus, the primary aim of the present research is to examine whether a group in an unfavorable position in the Swedish labor market, i.e., Arab-Muslim males, is implicitly associated with more negative attributes, and more specifically with lower work productivity (relative to native Swedish males). ${ }^{1}$

Previous research has shown that people in the U.S. generally possess more negative implicit and explicit attitudes (i.e., unfavorable dispositions) toward Arab-Muslims relative to other ethnic groups (Nosek et al., 2007). Similarly, in Sweden, Ekehammar et al. (2003) have found this to be the case when examining students' attitudes toward a more general category of immigrants in Sweden. The present study contributes to the extant research literature by also investigating whether Arab-Muslims are specifically associated with negative attributes related to low levels of work productivity. In other words, we are interested in whether people's generalized set of beliefs (i.e., stereotypes) of Arab-Muslims include that they are incompetent, inefficient, dull, lazy etc. We are particularly interested in whether these implicit productivity stereotypes exist to a significant extent among employers whose job is to hire staff. We predicted that employers should implicitly associate Arab-Muslim (relative to native Swedish males) with attributes reflecting lower levels of productivity.

We also wanted to examine whether employers possess more general unfavorable dispositions (i.e., attitudes) toward this minority group. Mirroring the "productivity stereotypes", we expected them to have more negative implicit attitudes toward Arab-Muslim males than native Swedish males. An additional goal was to examine to what extent the implicit attitudes and stereotypes measured by the Implicit Association Test (see the following section for a detailed description) diverge from their explicit counterparts captured by self-report measures. We anticipated that the

\footnotetext{
1 "Arab-Muslims" is a description of the group that we believed is best suited to describe the group. We realize that there are individuals with these names that do not consider themselves either Arabs or Muslims. However, these individuals may nevertheless be subject to the same level of discrimination, if they are perceived by others as belonging to that group, because of names or looks.
} 
explicit measures should give a more modest picture of this type of prejudice. The reasons for this are twofold. First, people will likely be motivated to appear socially desirable. Second, they may not be aware of their associations. As noted above, it is generally agreed upon within social psychology that we often process information in an automatic mode (for an overview of dual process models, see Chaiken \& Trope, 1999), and research shows that people frequently form associations of stimuli without conscious intent (see De Houwer et al., 2001 for a review). In light of this, there is reason to believe that automatically formed associations, which we do not consciously reflect upon, could play a substantial role in discrimination (Bertrand et al., 2005).

\section{The Implicit Association Test}

The Implicit Association Test (IAT; Greenwald et al., 1998) is a computerized response latency measure designed to tap individual differences in automatic associations between concepts and attributes. ${ }^{2}$ The IAT is the most widely used and reliable implicit measure to date (De Houwer, 2001). It is important to note that it assesses relative differences in strengths of associations. Thus, when we say that Arab-Muslims are associated with low productivity, this is not in an absolute sense. Rather, it means that Arab-Muslims are more easily associated with attributes reflecting low productivity compared with native Swedes. Notably, then, the IAT is an appropriate measure if one wants to relate it to discrimination because discrimination per definition involves differential treatment that favors one group over the other.

The IAT measures association strength by having participants sort stimuli representing four concepts into only two response categories that each includes two of the four concepts. The method rests on the assumption that more strongly associated concepts, when mapped together on the same response category, would yield a quicker response. Let us explain by referring to the attitude-IAT used in the present research. Here, when instructed to respond to Arab-Muslim names and unpleasant words by pressing the same response key in one part of the experiment, participants are expected to respond faster than when in another part of the experiment they are being instructed to press the same key for Arab-Muslim names and pleasant words. This pattern of response latencies would indicate the existence of stronger association of Arab-Muslims (than of native Swedes) with a negative evaluation, and a stronger association of native Swedes (than

\footnotetext{
${ }^{2}$ For a demonstration, visit the Project Implicit website at: https://implicit.harvard.edu/implicit/
} 
of Arab-Muslims) with a positive evaluation. The same logic applies to our stereotype-IAT which specifically uses words reflecting high (e.g., ambitious) versus low productivity (e.g., ineffective) instead of words that are simply pleasant (e.g., happiness) or unpleasant (e.g., misery).

Importantly, IAT-responses reflect the type of association between ethnicity and level of productivity that we are primarily interested in because they do not rely on elaborate thinking, introspection, or conscious preferences of one pairing over the other. Rather, the responses reflect intuitive tendencies to associate certain concepts with certain attributes (Greenwald et al, 1998). Furthermore, responses in the IAT are extremely difficult to fake (see Steffens, 2004).

\section{Experiment 1}

This experiment examined whether a negative implicit attitude bias toward Arab-Muslim males exists in a sample of employers. We further wanted to find out to what extent the implicit attitudes mirrored their explicit counterparts.

\section{Methodology}

\section{Participants}

Participants were 158 employers ( 80 males, 78 females) ${ }^{3}$ responsible for the recruitment of staff at various companies situated in Stockholm and Gothenburg, Sweden. They were paid 100 SEK (approximately 11 euros) for participation. Mean age was $43.41(\mathrm{~S} D=10.95)$ years. The employers were randomly selected from job advertisements involving twelve different occupations $^{4}$ that appeared in the database provided by the Swedish Labor Market Board (AMS) during a time period stretching from August, 2006 to February, 2007.

\section{Apparatus}

The participants used their own computers at home, or at work. Since Inquisit ${ }^{5}$ includes an automatic check for compatibility and adequate system performance, it was ensured that all computers met the specific requirements. All trials were recorded locally on the participant's computer using DirectX technology to ensure reliable millisecond accuracy. The data were then

\footnotetext{
${ }^{3}$ There were no effects of age or gender on the IAT-scores in this or in the second experiment. These results are available upon request. Further, not a single employer with an Arab-Muslim background participated in the study.

${ }^{4}$ See Carlsson \& Rooth (2007) for details.

${ }^{5}$ See www.millisecond.com for more information about the software.
} 
sent through a Secured Sockets Layer connection to a secured website, which ensured maximum confidentially. Note that internet connection quality, screen size, resolution and refresh rate et cetera do not affect the results.

\section{Measures}

\section{Implicit measure}

The implicit measure consisted of an attitude-IAT which followed the recommendations by Nosek et al. (2005). In the IAT, the two keys, "d" and "k", are mapped to categories on the left and right side of the computer screen, respectively. Using these keys, the participants were instructed to classify the stimuli words appearing one by one in the middle of the screen into the category to which they belong. The IAT:s used in the present research contained seven blocks of classifying tasks. See Table I in the Appendix for an overview. In all of our experiments, the target categories were "Arab-Muslim men" and "Swedish men" and the stimuli were ArabMuslim- and native Swedish-sounding male names. Furthermore, the design presented next was also followed in Experiment 2.

The first block consisted of 20 trials where the participant learned the target categories by classifying the target stimuli (e.g., Ali, Erik) into the two target categories ("Arab-Muslim men" versus "Swedish men"). The second block had the participant learn the attribute categories by classifying the attribute stimuli for another 20 trials. In this Arab-Muslim attitude IAT, the attribute labels were "positive" and "negative" and the stimuli were words that were either positively or negatively valenced (e.g. happiness, misery).

The third block was a pairing practice block where the participant sorted both the target and the attribute stimuli for 24 trials into the four different categories - using two keys ("d" and " $\mathrm{k}$ "). (Note that the category labels on top of the screen always helped the participant remember which key ("d" or "k") should be paired with which category.) In this block, the attribute category "negative" shared response key with the target category "Swedish men", whereas the attribute category "positive" shared response key with the target category "Arab-Muslim men". This pairing is referred to as the incongruent pairing, since it was assumed that this pairing is incompatible with the participants' automatic associations.

In the fourth block, participants continued to sort both target and attribute stimuli into the four different categories (in the same manner as in Block 3) but this time for 40 trials. The fifth block 
involved relearning how to sort the target stimuli with the reverse key mapping. That is, those participants who earlier had the category "Arab-Muslim men" mapped to "d" now had it mapped to "k", and "Swedish men" to "d". This block consisted of 40 trials.

The sixth block was a pairing practice block where the participant again sorted both target and attribute stimuli into the four categories for 24 trials. In this block, the attribute category "positive" shared response key with the target category "Swedish men", whereas the attribute category "negative" shared response key with the target category "Arab-Muslim men". This pairing is referred to as the congruent pairing, since it was assumed that this pairing is compatible with the participants' automatic associations. In the seventh block the participant continued to sort both target stimuli and attribute stimuli into the four categories (in the same manner as in Block 6), but now for 40 trials.

During the whole test, on any trial when the participants made an error, a large red X was presented on the screen, slightly below the stimulus, and the participant had to make the right key choice to proceed. The response times reflected the time from that the stimuli were presented until participants chose the correct key response. The participants were repeatedly reminded that they had to sort the stimuli fast, but that they should try not to make errors.

Since the combined parts are done with both normal and reversed key mapping, it is possible to calculate differences in response latencies between these two critical parts of the test. In this case, if the part of the test with "Arab-Muslim men" + "Unpleasant"/"Swedish men" + "Pleasant" generally has lower response latencies than "Swedish men" + "Unpleasant"/"ArabMuslim men" + "Pleasant", this suggests that there is an automatic attitude preference for native Swedish men over Arab-Muslim men.

Finally, the order of the presentation of the compatible versus incompatible parts in the IAT has typically been found to have only a small effect on the IAT score. We chose to administrate the incompatible part first which is likely to provide a lower, more conservative estimate of the IAT score than presenting the compatible part first (Nosek et al., 2005).

Table I presents an overview of the present attitude-IAT. Table II presents the labels and stimuli used in Experiment 1 and 2, respectively. It should be noted that the categories and stimuli were carefully chosen on the basis of extensive pre-testing (see Agerstrom et al., 2007 for details). 
*** Table I here ***

*** Table II here $* * *$

\section{Explicit measure}

The explicit measure consisted of a Feeling thermometer (see Nosek et al., 2005).

It asked the participants to rate their positive or negative feelings on a ten-point scale $(1=$ very negative feelings, $10=$ very positive feelings) toward Arab-Muslim men and Swedish men.

\section{IAT scoring procedure}

Following standard procedure, a D-value was calculated based on the participants' response latencies for the congruent vs. incongruent trials (see Greenwald et al., 2003 for details on scoring). A positive D-value reflects an implicit negative attitude bias toward Arab-Muslim men relative to native Swedish men (in the attitude IAT) and an implicit association that Arab-Muslim men are more low-performing relative to native Swedish men (in the stereotype-IAT). A negative $D$-value suggests the opposite.

Notably, the D-measure is a measure of an individuals' effect size on the IAT, and it resembles Cohen's d, but its strength should be interpreted as roughly twice that of Cohen's d (Greenwald et al, 2003), with a $D$-value of 0 suggesting no association at all. In reporting the results, we will present them in the same manner as in Nosek et al. (2007), showing the share of the sample that evidenced at least a slight $D$-score of .15 , which is a rather conservative cut-off score.

\section{Procedure}

We contacted the employers by phone and invited them to participate in a study on inclusion and exclusion processes related to the recruitment of staff. We then also explicitly stated that we had observed the hiring process of the advertised vacancy, and therefore we only invited the person responsible for the hiring to participate. 


\section{Results}

As predicted, the response times were higher in the incompatible condition ("Arab-Muslim men" + "Positive"/"Swedish men" + "Negative") than in the compatible ("Arab-Muslim men" + "Negative"/"Swedish men" + "Positive"), mean difference $=350 \mathrm{~ms} ; D=.64, S D=.31, t(157)=$ 18.20, $p<.001$. That is, the employers more easily associated Arab-Muslim men with negative attributes and native Swedish men with positive attributes than they associated Arab-Muslim men with positive attributes and native Swedish men with negative attributes. Intriguingly, 148 (94\%) employers showed at least a slight positive IAT-effect, while only two employers showed the reverse pattern. ${ }^{6}$

With respect to the explicit measure, $83(53 \%)$ employers explicitly stated in conjunction with the feeling thermometer that they have less positive feelings toward Arab-Muslim men $(M=$ $5.28, S D=1.72)$ than toward Swedish men $(M=6.73, S D=1.78), t(157)=7.99, p<.001$. Notably, the participants' IAT scores were only marginally related to the ratings given in response to the feeling thermometer $r(158)=.16, p=.05$.

In summary, these results show that the employers possess an implicit attitude bias in that they have more negative implicit attitudes toward Arab-Muslim men relative to Swedish men. They also showed an explicit negative attitude bias toward Arab-Muslims. However, the employers' explicit responses were only weakly related to their implicit attitudes, and compared with the IAT, the explicit questionnaire yielded a substantially smaller attitude bias.

\section{Experiment 2}

Experiment 1 demonstrated the existence of a general negative implicit attitude bias toward ArabMuslims in the employer sample. In Experiment 2 we wanted to be more specific and thus examined whether Arab-Muslim males are also implicitly associated with less work productivity, using a new sample of employers.

\section{Methodology}

Participants

\footnotetext{
${ }^{6}$ For the sake of external validity, the same attitude-IAT was administered to 87 university students (mean age 24.29 years, $S D=5.66)$ in the laboratory. The IAT-score $(D=.50)$ was similar to that of the employer sample.
} 
Participants were 193 employers (99 males, 94 females) responsible for the recruitment of staff at various companies situated in Stockholm and Gothenburg, Sweden. They were paid 500 SEK (approximately 55 euros) for their participation. Mean age was 44.92 ( $\mathrm{S} D=11.01$ ) years. The employers were randomly selected from job advertisements pertaining to twelve different occupations, appearing in the database provided by the Swedish Labor Market Board (AMS) during a time period stretching from May, 2005 to February, 2006.

\section{Implicit measure}

The implicit measure used in the present experiment consisted of a stereotype-IAT. It only differed from the attitude-IAT used in Experiment 1in that it used the attribute labels "highperforming" and "low-performing" with associated stimuli words (e.g., "productive" and "lazy"; see Table II).

\section{Explicit measure}

The explicit measures used in this experiment consisted of performance stereotype and hiring preference ratings, respectively. The former asked the participants to assess the general work performance of native Swedish relative to Arab-Muslim males. It included five response alternatives ranging from "Swedish men perform much better [slightly better] at work than ArabMuslim men" to "Swedish and Arab-Muslim men perform equally well at work" to "ArabMuslim men perform [slightly better] much better at work than Swedish men". These responses were coded so that -2 reflected superior, and -1 slightly better, performance in favor of ArabMuslims, whereas +2 reflected superior, +1 slightly better, performance in favor of Swedes. Equal performance was coded as 0.

The hiring preference task asked the employers to choose which of the two ethnic groups (Arab-Muslims versus native Swedes) they generally prefer hiring when recruiting staff. Unlike the stereotype rating task, this newly formed measure was not specifically intended to match the IAT. Rather than merely assessing beliefs regarding productivity, the hiring preference task was supposed to measure the employers' overt hiring preferences in the context of recruiting staff. In response to this measure, they were instructed to mark one of the following five alternatives: "When hiring staff I strongly [slightly] prefer Swedish males to Arab-Muslim males", or "When hiring staff I strongly [slightly] prefer Arab-Muslim males to Swedish males", or "When hiring 
staff I do not prefer one group to the other". A strong preference for Arab-Muslim was coded as -2 , a slight preference as -1 , whereas a strong preference for Swedish males was coded as +2 , a slight preference as -1 . A neutral response was coded as 0 . $^{7}$

\section{Procedure}

The procedure followed that of Experiment 1.

\section{Results}

As predicted, the response times were higher in the incompatible condition ("Arab-Muslim men" + "High Performance"/"Swedish men" + "Low Performance") than in the compatible ("ArabMuslim men" + "Low Performance"/"Swedish men" + "High Performance"), mean difference = $193 \mathrm{~ms} ; D=.38, S D=.34, t(192)=11.16, p<.001$. Stated in another way, the employers more easily associate Arab-Muslim men with low-performing attributes and native Swedish men with high-performing attributes than they associate Arab-Muslim men with high-performing attributes and native Swedish men with low performing attributes. In fact, 150 (78\%) employers exhibited at least a slight positive D-value. Thirteen participants $(7 \%)$ showed the reverse pattern. ${ }^{8}$

With respect to the performance stereotype rating task, Arab-Muslim males were generally explicitly perceived as less productive than Swedish males, $(M=.12, S D=.50), t(192)=3.49, p$ $<.001$. Yet, only 23 participants $(12 \%)$ explicitly stated that native Swedish men are slightly or much more high-performing at work than Arab-Muslim men. Interestingly, no significant correlation emerged between the stereotype IAT and the performance stereotype rating task, $r(193)=.53, p=.46$.

Notably, responses to the hiring preference task revealed that 53 percent of the employers said they at least slightly prefer native Swedish males to Arab-Muslim males when recruiting staff. Moreover, the explicit hiring preference ratings were significantly correlated with the IAT, $r(193)$ $=.23, p<.001$.

In summary, it is clear that the employers automatically associate Arab-Muslim males with less productivity. Another interesting finding was that the performance stereotype IAT showed a

\footnotetext{
${ }^{7}$ These questions did not attempt to distinguish between the economic concepts of taste-based and statistical discrimination (see Altonji \& Blank, 1999).

${ }^{8}$ Again, for external validity reasons, this stereotype-IAT was administered to the same university students who completed the attitude-IAT in the laboratory. The IAT-score $(D=.40)$ was similar to that of the employer sample.
} 
positive correlation with whom the employers said they preferred when recruiting staff. Although it cannot be taken for granted that the employers' reported hiring preference is an accurate reflection of their actual real-life decisions, this nonetheless suggests that the implicit performance stereotypes measured in the present IAT may be capable of predicting hiring discrimination.

\section{Discussion}

Since it is well documented that Arab-Muslims, and especially males, are subject to substantial labor market discrimination in Sweden, we chose to study employer's implicit associations toward this ethnic group. As predicted, the results clearly show that implicit prejudice toward this group exists as manifested in the strong IAT-effects and the large number of employers who exhibited a negative implicit disposition (i.e., negative attitude) toward Arab-Muslim males, and specifically associated this group relative to native Swedish males with lower productivity.

While the participants' explicit responses toward Arab-Muslim males were in general agreement with what we found in the IAT, in that they also revealed the existence of a negative attitude bias and stereotypes reflecting lower levels of productivity, the proportion that in fact did so was substantially smaller. With respect to attitudes, whereas 49 percent of the employers explicitly reported having more negative feelings toward Arab-Muslim than native Swedish males, the IAT showed that no less than 94 percent evidenced a slight implicit attitude bias. The implicit-explicit discrepancy was even more pronounced for the productivity stereotypes. Among the employers 78 percent implicitly associated Arab-Muslim males with less productivity, but only 12 percent explicitly stated that this target group performs less well than native Swedish males. When the employers were explicitly asked whether they prefer native Swedish to ArabMuslim males when hiring staff, half of them said they did so. Although this is not a trivial proportion, the IAT suggests that a greater portion possesses a negative productivity stereotype of Arab-Muslim males.

Importantly, in research under way (Rooth, 2007) fictitious job applications that were matched on skills and which only differed with respect to the name of the applicant (ArabMuslim vs. Swedish) were sent to posted job openings. Those recruiters who were responsible for the hiring (or rather the interview) decision were a few months later contacted and asked to take the IAT and to give ratings on explicit prejudice measures. The study finds that the implicit 
productivity stereotypes examined in the present research are capable of predicting real-life hiring decisions, whereas their explicit counterparts do not. More specifically, it was found that recruiters who automatically associate Arab-Muslims with low-performing attributes are less likely to choose to invite Arab-Muslims and more likely to invite Swedes for job interviews.

There are also sound theoretical reasons for why implicit stereotypes (and attitudes) could affect hiring decisions. For instance, it may be that in many instances hiring decisions tend to be automatic in nature. Given that automatic associations are thought to be more influential in situations where there is a high degree of automaticity, and where deliberate and more time consuming cognitive processes are mitigated (Greenwald et al., in press), it may be that they play a more important role when, for example, recruiters have to do a quick initial screening among a number of different job applications, as well as when cognitive load, and fatigue enter the equation. Since the IAT is assumed to capture the kind of 'intuitive' processes implied in the aforementioned example, one could expect it to be particularly useful in predicting outcomes in such contexts.

Importantly, the findings from the present study coupled with the aforementioned Rooth (2007) data have numerous practical implications. For instance, with respect to growing educational efforts made by companies in order to increase awareness of work related prejudice among their employers, we argue that it would be beneficial to use implicit measures such as the IAT to evaluate whether these education programs have indeed had the desired effect. This claim rests on the assumption that the IAT is a better and more convincing indicator of attitudes and stereotypes than are explicit evaluation tools. There are two main reasons for this. First, the method is not plagued by social desirability. Second, it does not require people to have introspective access to all their cognitions and associations. Thus, if the goal is to be able to demonstrate effects of education programs on genuine stereotypical associations, the IAT offers a promising possibility.

Another important practical implication concerns the hiring process. Given that hiring decisions are made on more subtle grounds (e.g., race) than job related qualifications, it is important for companies to ensure that recruiters adopt more stringent and thorough evaluation criteria when assessing the suitability of job applicants. Demanding recruiters to rate the applicant on several pre-established job relevant dimensions is one way to go if one wants to reduce the impact of "gut-feelings" on hiring decisions. Increasing accountability by requiring 
recruiters to motivate their hiring decisions could also contribute to a more objective evaluation process. Of course, adopting more extensive and thorough hiring procedures may appear to be costly at a first glance. However, we believe that companies may lose important human capital if intuitions are allowed to govern hiring processes and decisions.

In conclusion, the IAT offers a new approach to understanding work related prejudice and could serve as an important tool for making prejudiced individuals in general, and employers working with recruiting staff in particular, become aware of their own cognitive bias. In the long run, we believe this to be an important step in creating a fair job market. 


\section{References}

Agerström, J., Carlsson, R., \& Rooth, D. (2007). "Ethnicity and obesity: evidence of implicit work performance stereotypes in Sweden”, IFAU Working Paper 2007:20.

Altonji, J., \& Blank, R. (1999). "Race and Gender in the Labor Market", in Ashenfelter O., \& D. Card (Eds.), Handbook of Labor Economics, Vol 3., Elsevier, North Holland, pp. 3143-3159.

Bargh J., Chen, A., \& Burrows, L. (1996). "Automaticity of social behaviour: Direct effects of trait construct and stereotype activation of action", Journal of Personality and Social Psychology, Vol. 1, pp. 1-40.

Bertrand M, Chugh, D., \& Mullainathan, S. (2005). "New Approaches to Discrimination: Implicit Discrimination”, American Economic Review, Vol. 95 No. 2, pp. 94-98.

Bertrand M., \& Mullainathan, S. (2004). “Are Emily and Greg More Employable than Lakisha and Jamal? A Field Experiment on Labor Market Discrimination”, American Economic Review, Vol. 94, pp. 991-1013.

Carlsson M., \& Rooth, D. (2007). "Evidence of Ethnic Discrimination in the Swedish Labor Market Using Experimental Data”, Labour Economics, Vol. 14, pp. 716-729.

Chaiken, S., \& Trope, Y. (1999). Dual-process theories in social psychology, New York: Guilford Press.

De Houwer, J. (2001). "A structural and process analysis of the Implicit Association Test", Journal of Experimental Social Psychology, Vol. 37 No. 6, pp. 443-451.

De Houwer, J., Thomas, S., \& Baeyens, F. (2001). "Associative learning of likes and dislikes: A review of 25 years of research on human evaluative conditioning". Psychological Bulletin, Vol. 127, pp. 853-869.

Devine, P. (1989). "Stereotypes and prejudice: Their automatic and controlled components", Journal of Personality and Social Psychology, Vol. 56 No. 1, pp. 5-18.

Ekehammar, B., Akrami, N., \& Araya, T. (2003). "Gender differences in implicit prejudice", Personality and Individual Differences, Vol 34. No. 8, pp. 1509-1523.

Green, A., Carney, D. R., Pallin, D., Iezzoni, L., and Banaji, M. (2007) "Implicit Bias among Physicians and its Prediction of Thrombolysis Decisions for Black and White Patients", Journal of General Internal Medicine, 22(9), 1231-1238.

Greenwald, A., McGhee, D., \& Schwartz, J. (1998). "Measuring individual differences in implicit cognition: The implicit association test", Journal of Personality and Social Psychology, Vol. 74 No. 6, pp. 1464-1480.

Greenwald, A., Nosek, B., \& Banaji, M. (2003). "Understanding and Using the Implicit Association Test: I. An Improved Scoring Algorithm", Journal of Personality and Social Psychology, Vol. 85 No. 2, pp. 197-216.

Greenwald, A., Poehlman, A., Uhlmann, E. L., \& Banaji, M. (in press). “Understanding and using the implicit association test: III. Meta-analysis of predictive validity". Journal of Personality and Social Psychology.

Nosek, B., Greenwald, A., \& Banaji, M. (2005). "Understanding and using the Implicit Association Test: II. Method variables and construct validity", Personality and Social Psychology Bulletin, Vol 31 No. 2, pp. 166-180. 
McConnell, A. R., and Leibold, J. M. (2001) "Relations Among the Implicit Association Test, Discriminatory Behavior, and Explicit Measures of Racial Attitudes", Journal of Experimental social Psychology, 37, 435-442.

Nosek, B., Smyth, F., Hansen, J., Devos, T., Lindner, N., Ranganath, K., Smith, C., Olson, K., Chugh, D., Greenwald, A., Banaji, M. (2007). "Pervasiveness and correlates of implicit attitudes and stereotypes", European Review of Social Psychology, Vol. 18, pp. 36-88.

Phelps, E. (2006). "Emotion and cognition: Insights from studies of the human amygdala". Annual Review of Psychology, Vol. 24, pp. 27-53.

Rooth, D. (2007). "Implicit Discrimination in Hiring: real world evidence". IZA Discussion Paper \#2764, Bonn, Germany.

Rudman, L. A., and Lee, M. R. (2002). "Implicit and Explicit Consequences of Exposure to Violent and Misogynous Rap Music", Group Processes and Intergroup Relations, 5, 133-150.

Steffens, M. (2004). "Is the Implicit Association Test Immune to Faking?", Experimental Psychology, Vol. 51 No. 3, pp. 165-179.

Uhlmann, E. L., \& Cohen, G. (2007). "I think, therefore it's true: Effects of self-perceived objectivity on hiring discrimination". Organizational Behavior and Decision Processes, Vol. 104, pp. 207-223. 


\section{Tables}

Table I. Overview of the IAT

\begin{tabular}{|c|c|c|c|c|c|}
\hline Task \# & Treatment & $\begin{array}{c}\text { Category Label \#1 } \\
\text { (Typed Key = D) }\end{array}$ & Target stimuli & $\begin{array}{c}\text { Category Label \#2 } \\
\text { (Typed Key = K) }\end{array}$ & $\begin{array}{c}\mathbf{N} \\
\text { Trials }\end{array}$ \\
\hline 1 & Name Match & Muslim Men & Ali vs. Lars & Swedish Men & 20 \\
\hline 2 & $\begin{array}{l}\text { Attribute } \\
\text { Match }\end{array}$ & Positive & Happiness vs. Pain & Negative & 20 \\
\hline 3 & $\begin{array}{l}\text { Incongruent } \\
\text { Pairing }\end{array}$ & $\begin{array}{c}\text { Muslim Men } \\
\text { or } \\
\text { Positive }\end{array}$ & $\begin{array}{c}\text { Ali vs. Lars } \\
\text { or } \\
\text { Happiness vs. Pain }\end{array}$ & $\begin{array}{c}\text { Swedish Men } \\
\text { or } \\
\text { Negative }\end{array}$ & 24 \\
\hline 4 & $\begin{array}{l}\text { Incongruent } \\
\text { Pairing }\end{array}$ & $\begin{array}{c}\text { Muslim Men } \\
\text { or } \\
\text { Positive }\end{array}$ & $\begin{array}{c}\text { Ali vs. Lars } \\
\text { or } \\
\text { Happiness vs. Pain }\end{array}$ & $\begin{array}{c}\text { Swedish Men } \\
\text { or } \\
\text { Negative }\end{array}$ & 40 \\
\hline 5 & $\begin{array}{c}\text { Reverse } \\
\text { Keys }\end{array}$ & Swedish Men & Ali vs. Lars & Muslim Men & 40 \\
\hline 6 & $\begin{array}{l}\text { Congruent } \\
\text { Pairing }\end{array}$ & $\begin{array}{c}\text { Swedish Men } \\
\text { or } \\
\text { Positive }\end{array}$ & $\begin{array}{c}\text { Ali vs. Lars } \\
\text { or } \\
\text { Happiness vs. Pain }\end{array}$ & $\begin{array}{c}\text { Muslim Men } \\
\text { or } \\
\text { Negative }\end{array}$ & 24 \\
\hline 7 & $\begin{array}{l}\text { Congruent } \\
\text { Pairing }\end{array}$ & $\begin{array}{c}\text { Swedish Men } \\
\text { or } \\
\text { Positive }\end{array}$ & $\begin{array}{c}\text { Ali vs. Lars } \\
\text { or } \\
\text { Happiness vs. Pain }\end{array}$ & $\begin{array}{c}\text { Muslim Men } \\
\text { or } \\
\text { Negative }\end{array}$ & 40 \\
\hline
\end{tabular}




\section{Table II. IAT Labels and stimuli}

\begin{tabular}{|l|l|}
\hline Category labels & Stimuli \\
\hline $\begin{array}{l}\text { Target labels } \\
\text { Muslim men }\end{array}$ & $\begin{array}{l}\text { Ali, Ameer, Mohammed, Said, Reza, Hassan } \\
\text { Erik, Lars, Karl, Johan, Anders, Per }\end{array}$ \\
\hline $\begin{array}{l}\text { Attribute labels (attitude-IAT) } \\
\text { positive } \\
\text { negative }\end{array}$ & $\begin{array}{l}\text { happiness, love, joy, sun, laughter, wonderful } \\
\text { murder, pain, misery, death, evil, hurt }\end{array}$ \\
\hline $\begin{array}{l}\text { Attribute labels (stereotype-IAT) } \\
\text { high-performing } \\
\text { low-performing }\end{array}$ & $\begin{array}{l}\text { effective, productive, hardworking, ambitious, goal-oriented } \\
\text { ineffective, incompetent, slow, lazy initiative-lacking }\end{array}$ \\
\hline
\end{tabular}

